\title{
Erratum to: Three-dimensional dynamic simulation of elastocapillarity
}

\author{
Jesus Bueno - Hugo Casquero • Yuri Bazilevs • Hector Gomez
}

Published online: 3 July 2017

(C) Springer Science+Business Media B.V. 2017

\section{Erratum to: Meccanica \\ DOI 10.1007/s11012-017-0667-4}

Due to an unfortunate turn of events during processing of this article essential data was omitted from Fig. 5.
Figure 5 has been updated with the correct version in the article itself and should be regarded as the final version by the reader.

The original version of this article was revised.

The online version of the original article can be found under doi:10.1007/s11012-017-0667-4.

J. Bueno $(\bowtie) \cdot$ H. Casquero

Departamento de Métodos Matemáticos e de

Representación, Universidade da Coruña, Campus de

Elviña, 15192 A Coruña, Spain

e-mail: jesus.bueno@udc.es

Y. Bazilevs

Department of Structural Engineering, University of California, San Diego, 9500 Gilman Drive, La Jolla,

CA 92093, USA

H. Gomez

School of Mechanical Engineering, Purdue University, 585 Purdue Mall, West Lafayette, IN 47907, USA 